\title{
A CELEBRAÇÃO DO OUTRO NA CONSTITUIÇÃ̃O DA IDENTIDADE
}

\author{
Maria José R. F. Coracini
}

RESUMO: Cet article a pour objectif de problématiser l'identité subjective et nationale, vue comme étant homogène et fixe, à partir de la presse contemporaine brésilienne. Résultat d'une recherche sur l'identité du Brésilien constitué par le regard de l'autre - étranger (américain et européen) - que l'on célèbre et en même temps on refuse, on constate une assimilation de représentations contradictoires où cohabitent les discours du colonisateur, du colone et du colonisé, de la soumission et de l'ufanisme.

PALAVRAS-CHAVE: discurso, sujeito, identidade, identificação, interdiscurso, imprensa, memória.

Partindo do pressuposto extraído da psicanálise lacaniana e das teorias do discurso segundo o qual o outro nos constitui assim como constitui o nosso discurso, é possível afirmar que as representações que fazemos do estrangeiro e as representações que o estrangeiro faz de nós atravessam, de modo constitutivo, o sentimento de identidade subjetiva, social e nacional. Assim como nomear é dar realidade ao objeto, é possível afirmar que falar de um povo ou de um grupo social e até mesmo de um indivíduo é dar-lhes existência, fazê-los serem e acreditarem que são ou que

Maria José R.F. Coracini é professora da Universidade Estadual de Campinas. 
existem. Não é à toa que se diz que falar de alguém é manter esse alguém vivo, na memória do outro e, portanto, na sua própria memória...

Assim, ser brasileiro é ser o que dizem que somos e ver o outro do modo como o vemos. Mas nem sempre falar é sinônimo de reter na memória, a não ser que estejamos nos referindo à memória cognitiva, à consciência. Entretanto, o que somos e o que pensamos ver está carregado do dizer alheio, dizer que nos precede ou que precede nossa consciência e que herdamos, sem saber como nem porquê, de nossos antepassados ou daqueles que parecem não deixar rastros. O que somos e o que vemos está carregado, portanto, do que ficou silenciosamente abafado na memória discursiva, como um saber anônimo, esquecido. A psicanálise nos lembra que é preciso esquecer, matar o pai que simboliza a lei, a regra, a moral, a tradição, ultrapassá-lo, se possível, para que, internalizado, ele sobreviva para sempre. É na medida em que se internaliza um traço que ele se faz corpo no corpo do sujeito, que ele se faz presente, imperceptível, mas real, no real do inconsciente, permitindo identificações.

Com base nesses princípios e conhecendo a força da mídia na construção do imaginário, responsável pelo sentimento de identidade que nos une para formar uma nação, um grupo social e, ao mesmo tempo, nos dá a medida da nossa singularidade, concedendo-nos a ilusão da unidade e da totalidade - efeito do congelamento, ainda que momentâneo, do discurso veiculado pela mídia - foram analisados textos publicados na imprensa escrita ${ }^{1}$ - artigos em jornais e revistas de grande circulação - que permitem entrever fios de identificações responsáveis pelas representações do estrangeiro sobre o Brasil e sobre o brasileiro e representações do brasileiro sobre o estrangeiro e sobre si mesmo.

\section{IDENTIDADE, SUJEITO E IMPRENSA}

A escolha da imprensa escrita se deve à expansão de sua circulação, nos dias de hoje, em que os textos jornalísticos ganham espaço até mesmo na sala de aula e na internet, o que lhes confere maior poder na constituição de sentimentos de identidade. Como lembra SILVA (2000), a identidade, quer nacional, individual ou subjetiva, é produzida ou construída socialmente por aquele(s) a quem se atribui maior poder, e, portanto, a quem se concede autoridade para, legitimamente, dizer verdades ou a verdade sobre os fatos, o povo, o indivíduo. É(são) essa(s) verdade(s) que, internalizada(s), garante(m), como dizíamos, a possibilidade de o ser hu-

${ }^{1}$ Este artigo é parte do Projeto Integrado CNPq "Interdiscurso e Identidade no Discurso Didático-Pedagógico (LM e LE)" e recebeu auxílio financeiro da FAPESP.

202 
mano se constituir como sujeito da linguagem, isto é, sujeito do discurso, atravessado por ela(s), e, assim, atravessado pelo(s) outro(s), presente(s), mas escondido(s) na opacidade do esquecimento. Alguns desses discursos, repetidos e ao mesmo tempo transformados em narrativas, vão constituindo a memória discursiva de um povo e construindo uma nação. Como afirma Bhabha (1998), é o que ele chama de discurso pedagógico que é responsável pela construção do sentimento de nacionalidade e, portanto, pelas auto e hétero-representações. Segundo ele, o discurso pedagógico simplifica a realidade, transformando-a numa narrativa que a torna verdade inquestionável, ao mesmo tempo em que facilita sua assimilação.

Não há outro modo de se dizer que não seja através do olhar e da voz do outro. Basta lembrar o estádio do espelho de Lacan (1998), segundo o qual a criança, que ainda não formou uma auto-imagem, se vê ou se imagina a si própria refletida no espelho, literal e figurativamente, no "espelho do olhar do outro", que nomeia a imagem do espelho e, assim, lhe confere uma identidade, a partir dessa identificação. A formação do eu no "olhar" do outro inicia a relação da criança com os sistemas simbólicos, que passam a constituí-la de modo inconsciente. Dá-se, assim, a sua entrada nos vários sistemas de representação simbólica, dentre os quais a língua, a cultura e a diferença sexual. Os sentimentos contraditórios e não resolvidos que acompanham essa difícil entrada - aspectos-chave da formação inconsciente do sujeito - e que deixam o sujeito 'dividido', permanecem com ele por toda a vida. Entretanto, embora partido, cindido, o sujeito vivencia sua própria identidade como se ela estivesse reunida e "resolvida" ou unificada, resultado da fantasia de si mesmo como uma "pessoa" unificada, formada na fase do espelho. Nisso consiste a origem contraditória da "identidade" (NASIO, 1995).

Apesar da ilusão que se instaura no sujeito, a identidade não é inata nem natural, mas naturalizada, através de processos inconscientes, e permanece sempre incompleta, sempre em processo, sempre em formação.

O sujeito é, assim, fruto de múltiplas identificações - imaginárias e/ou simbólicas - com traços do outro que, como fios que se tecem e se entrecruzam para formar outros fios, vão se entrelaçando e construindo a rede complexa e híbrida do inconsciente e, portanto, da subjetividade. Rede essa que resulta da falta constitutiva do sujeito que, em vão, deseja preenchê-la, supri-la ao longo da vida, supri-la com o outro, objeto do seu desejo. Mas como o seu desejo é preencher a sua falta e o desejo do outro é também preencher a sua falta, o que o sujeito deseja é o desejo do outro, ou seja, que o outro o deseje.

Só podemos, pois, falar de identidade como tendo sua existência no imaginário do sujeito que se constrói nos e pelos discursos imbricados 
que o vão constituindo, dentre os quais, o discurso da ciência, do colonizado e da mídia. Sabemos que uma das características fundamentais do discurso jornalístico é atuar na institucionalização social de sentidos, contribuindo para a cristalização da memória do passado, bem como para a construção da memória do futuro. Trata-se de um discurso sobre que como tal, atua no efeito de linearidade e homogeneidade da memória. /.../ De modo geral, representa lugares de autoridade em que se efetua algum tipo de transmissão do conhecimento, já que o falar sobre transita na co-relação entre o narrar/descrever um acontecimento singular estabelecendo sua relação com um campo de saberes já reconhecido pelo interlocutor. (MARIANI, 1999, p. 60)

Assim, o discurso jornalístico colabora para a manutenção de certos discursos em circulação, ou seja, trabalha, no inconsciente, de modo a deixar viva a memória discursiva e, com isso, contribui para a manutenção (ou reforço) das relações sociais jurídico-políticas. Veículo de informação, a imprensa de modo geral provoca nos leitores ou ouvintes efeitos de verdade, como se não houvesse recortes, escolhas, interesses em jogo, ilusão que sustenta o mito da informatividade para poder dizer/relatar o que interessa a alguns. Não podemos esquecer que a imprensa funciona construindo um modelo de compreensão dos sentidos, instituindo uma ordem, isto é, organizando e fazendo circular os sentidos que interessam a instâncias que o dominam. Declarando-se comprometida com a verdade dos fatos, a imprensa finge não contribuir para a construção das evidências, atuando no mecanismo ideológico de produção das aparências de obviedade. Constitui nosso imaginário a idéia de que, se a imprensa não é o mundo, ela está autorizada a falar sobre ele, a retratá-lo, torná-lo compreensível ao leitor. Daí os efeitos de verdade que acaba provocando em seus leitores. Camufla, assim, seu caráter ideológico pelo pretenso compromisso com a verdade e, evidentemente, colabora para a construção do imaginário do leitor quando expõe ou sugere opiniões sobre o Brasil e os brasileiros, sobre outros países e os estrangeiros.

\section{REPRESENTAÇÕES NA MÍDIA}

Foram analisados textos escritos por brasileiros e textos escritos por estrangeiros, em que se tentou rastrear e, num segundo momento, comparar, as representações sobre o Brasil ou o povo brasileiro. Foi possível perceber aí a recorrência de algumas representações que poderiam ser sintetizadas em enunciados, abstraídos das matérias analisadas, que, por vezes, se cruzam e se imbricam no discurso, de modo conflituoso e heterogêneo. Tais enunciados naturalizaram-se, de modo que são encon- 
trados em diferentes textos, produzidos tanto por estrangeiros quanto por brasileiros. Num segundo momento, serão abordadas as representações que habitam os brasileiros a respeito do estrangeiro.

Entretanto, como é praticamente impossível falar do outro sem falar de si e vice-versa, é inevitável que, nos textos analisados, ao falar sobre o brasileiro, emerjam representações dos estrangeiros sobre si próprios e sobre sua cultura, e, ao falar do estrangeiro, aflorem representações de si nos textos redigidos por brasileiros sobre os estrangeiros, tomando uns e outros como ponto de referência o seu universo, já que só é possível observar o outro a partir das próprias referências ideológico-culturais.

\section{Representações do Brasil e dos brasileiros}

É preciso adiantar que os enunciados abaixo elencados e comentados resultam da análise dos textos, que apontam para imagens que, sabemos, constituem verdadeiros estereótipos da cultura do outro que, freqüentemente, são assumidos como verdades sobre si próprio.

Consideremos, então, os seguintes enunciados que procuram sintetizar as representações mais recorrentes:

\section{a) O brasileiro é desorganizado e indisciplinado}

Subjaz a esse enunciado a idéia de que existe um parâmetro ideal de organização - da vida social e da cidade, no caso que aqui trazemos e disciplina, na educação das crianças por exemplo, que não é seguido pelo brasileiro.

No suplemento "Mais!" da Folha de São Paulo (1997), foi recortada uma matéria sobre o Brasil, que se inicia afirmando que o conceito de centro é problemático, sobretudo em São Paulo, conforme testemunha Peter Burke, historiador inglês, depois de sua visita ao Brasil, o que evidencia a desorganização que aí reina. O silêncio é "menor" - o que pressupõe: 'do que no seu país'. Várias pessoas falam ao mesmo tempo e o que espanta mais é a atenção simultânea que o brasileiro é capaz de conceder a mais de um orador. As crianças permanecem na rua, comendo em restaurantes com os pais, depois da meia-noite: a pouca ou nenhuma disciplina, tomados os próprios parâmetros culturais, chocam os estrangeiros, europeus principalmente.

\section{b) O brasileiro é desonesto, caloteiro e explora os estrangeiros}

Sobre a desonestidade, causa estranhamento a cotação do câmbio paralelo nos jornais brasileiros ao lado do câmbio oficial. Kenneth Maxwell, 
outro historiador e brasilianista inglês, refere-se também ao calote que os estudantes costumam aplicar a restaurantes, comendo e saindo em bando sem pagar. Tal atitude o atraía na juventude e ao mesmo tempo provocavalhe estranhamento: em Cambridge era normal isso acontecer com os estudantes em lojas e alfaiates, mas era uma maneira de "acumular contas para os pais pagarem", bem diferente do que acontece no Brasil. Noutros artigos, os jornalistas fazem referência ao medo que sentem os países industrializados e o FMI de receberem calote do Brasil, sobretudo diante da recente mudança de governo federal. Outro texto, ainda, faz referência à exploração dos turistas gringos pelos cariocas. Fica, assim, evidenciada a desconfiança no povo brasileiro em geral, em confronto com a suposta honestidade e correição do povo e da cultura a que pertence o articulista.

O que chama a atenção nesses e noutros textos é o fato de as matérias se apresentarem como verdadeiras narrativas, episódios que provocam no leitor o efeito de ver(aci)dade: os fatos se encadeiam no tempo e no espaço, os enunciados são assertivos, não deixam dúvidas nem dão margem a questionamentos. Afinal, a voz do estrangeiro é sempre abalizada ou assim se crê...

c) Sob uma aparente cordialidade, o brasileiro é violento e desumano

Contardo Calligaris, por ter vivido durante seis anos no Brasil, sente-se autorizado a falar na primeira pessoa do plural, como se ele fosse brasileiro, maneira também de simular que, ao falar do outro, fala de si:

(S.1) - No Brasil, somos cordiais, lemos e praticamos os vínculos jurídicos como laços afetivos. Seguimos confundindo subordinação com submissão e, contra qualquer sistema abstrato de trocas e obrigações, preferimos a concretude complexa dos favores. [..] É misterioso para mim que a ostentação do consumo, banal nos Estados Unidos e na Europa, não se torne no Brasil fonte de vergonha. (FSP, 12/12/1999)

É curioso observar, na primeira parte do recorte (S.1), o uso da primeira pessoa do plural e, na segunda parte, da primeira pessoa do singular, fazendo, parece, o contraponto entre o que parecem ser qualidades ou hábitos (e aí o enunciador se inclui) e o olhar do enunciador ("É misterioso para mim...") que toma distância para mostrar o seu estranhamento e, portanto, a sua crítica como alguém que conhece muito bem os povos americano, europeu e brasileiro e, por isso, pode emitir juízos de valor.

E prossegue referindo-se às diferenças sociais que parecem não envergonhar o brasileiro como um comportamento que "em vez de abrir e alimentar a mobilidade social, cristaliza as distâncias" entre os segmentos 
sociais. Afirma ainda o psicanalista que

(S.2) - [a] aparente cordialidade gostosa é, assim, vazia: uma fábrica de eufemismos coletivos que ocultam a violência da divisão social e nos induzem a crer na existência de uma grande família nacional. [...] A familiaridade do brasileiro é hoje uma mentira que oculta a divisão social inconciliável.

Note-se o retorno do pronome "nós" ("...nos induzem a crer na existência de uma grande família nacional") que deixa dúvidas quanto ao referente: nós, brasileiros? Nós, estrangeiros? Ou ambos ao mesmo tempo? Mas, logo a seguir o uso da terceira pessoa do singular ("a familiaridade do brasileiro") aponta para um certo distanciamento (o enunciador não faz parte desse grupo) dando a entender que o juízo de valor é do estrangeiro sobre o brasileiro, o que parece funcionar como um argumento por autoridade, sobretudo se considerarmos que o autor é um psicanalista de renome no Brasil, que viveu em Porto Alegre durante seis anos.

Não resta dúvida de que há muito de verdade na denúncia apresentada por Contardo Calligaris, mas a generalização que é feita, sem um estudo mais profundo das causas, torna-a questionável e, até certo ponto, tendenciosa: afinal, por que nos Estados Unidos e na Europa a "ostentação do consumo" é "banal" e, portanto, não merece crítica (S.1)? Será que, nesse país e/ou nesse continente, todos têm as mesmas oportunidades de trabalho, de acesso aos bens de consumo? Ou será que sua superioridade tecnológica e econômica os autoriza a fazerem julgamentos apressados?

\section{d) Os brasileiros são gastadores e grandes consumistas}

Mais um estereótipo do brasileiro há muito propagado dentro e fora do Brasil: de que o brasileiro gasta mais do que ganha. Observemos o próximo recorte, extraído de um texto que, ao tratar do turismo na França, ...:

(S.3) - Gastadores, consomem três vezes mais do que a média dos estrangeiros. [...] individualistas, ávidos consumidores e muito exigentes quanto aos serviços [...], gastam cerca de 180 dólares por dia na França

Sabe-se que o fato de o brasileiro gastar muito constitui, para o mundo capitalista e, portanto, para o francês que deseja manter seu público consumidor, um aspecto positivo: talvez por isso mesmo, o brasileiro, presa fácil do desejo do outro, seja alvo de constantes bombardeios publicitários. Mas, considerando que o texto foi escrito por um estrangeiro, que se vê como fazendo parte de um povo austero, não há como não reconhecer o efeito de sentido de crítica, provocado, sobretudo, pela presença de adjetivos como "gastadores" e "ávidos consumidores" e pela frase: 
“...consomem três vezes mais do que a média dos estrangeiros”. É evidente que todo estereótipo se constrói a partir da observação e da experiência de alguns, mas a generalização, mais uma vez, fragiliza - ou deveria fragilizar - o efeito de constatação e de verdade veiculado por tais enunciados. Pena que muitas vezes os aceitamos e os internalizamos sem questionamento...

e) Os brasileiros confiam no "seu jeitinho"

Trata-se, desta vez, do famoso "jeitinho brasileiro", alvo de elogio e de críticas: (S.4) "Desembaraçados, acham que tudo se resolve só porque são brasileiros", diz o folheto distribuído pelo governo francês, segundo matéria publicada na revista VEJA (30/8/1995), intitulada "Combate à cara feia". Tal folheto, segundo o texto, tinha o intuito de mostrar como os franceses devem agir com relação aos povos que vêm visitar seu país.

Há quem interprete "o jeitinho brasileiro" - com o qual se resolvem todos os problemas, se burlam as leis - triunfo da vontade de poder (BACKES, 2000) ou como efeito de uma das vozes que constituem o brasileiro: a voz do colonizador que deixou seu país de origem em busca do gozo, de tudo o que poderia lhe dar prazer, do paraíso sem lei, sem censura (CALLIGARIS, 1996) e crê, ilusoriamente, tê-lo encontrado nas novas terras. Esse "jeitinho" que tudo resolve pode ser explicado como um efeito do sentimento oceânico de que fala Freud de tudo poder (onipotência) e de tudo saber (onisciência), que se traduz em esperteza, jogo de cintura, astúcia, mas que encobre outro sentimento forte de inferioridade que acomete o povo brasileiro e que se evidencia nos enunciados $\mathrm{g}$ e $\underline{\mathrm{h}}$.

\section{f) Os brasileiros fogem da responsabilidade}

Quanto à responsabilidade, um dos textos parece ser contundente (S.5): "Para evitar assumir a responsabilidade pelos atos ou opiniões e para fugir dos confrontos embaraçosos", os brasileiros criaram estratégias discursivas que o articulista denomina "esquiva retórica", por ele descrita como manifestações de "hábitos que estão enraizados nessa cultura". Locuções verbais do tipo "pode ser", "vamos ver", "se der", além de frases descompromissadas como "eu te ligo", "a gente se vê", "apareça lá em casa", afirma o autor, são escapadas e não promessas de um novo encontro. Tendo passado alguns anos no Brasil, o brasilianista inglês, Michael Kepp, declara, ainda, que o brasileiro tem dificuldade com o negativo, principalmente alguns cariocas que são "craques em convites sem fundos" (Folha de São Paulo - FSP -, 25/2/96). Claro está que se trata de um traço cultural que em 
nada compromete, mas, aos olhos do estrangeiro que acredita na transparência da linguagem e no sujeito consciente (o que diz é o que pensa e é o que faz), tal traço recebe outra interpretação. Só que o texto não trata da questão como um aspecto cultural que, como tal, não é consciente e que, por isso mesmo, não pode ser proposital ou intencional como leva a crer S.5 que começa com uma oração final: "Para evitar assumir a responsabilidade..."

Escusado é lembrar que, por detrás dos enunciados até aqui apresentados, escritos quer por brasileiros quer por estrangeiros, permanecem representações sobre a cultura do estrangeiro ou daquele que escreve, cultura que, por oposição ao que se diz da brasileira, é honesta, comprometida com a verdade do que diz e, portanto, com a transparência, o equilíbrio, a sinceridade, qualidades reputadas como ideais, em oposição radical ao outro - no caso, o brasileiro - sintomaticamente inferior e menos civilizado. Parece, assim, que o brasileiro guarda na memória o que sempre se disse ou se deu a entender - desde a época da colonização: que o Brasil é um país de ninguém, sem rei, sem fé e sem lei, o que tira dele as virtudes de um povo que respeita e que está sempre do lado da verdade e que, por isso mesmo, merece ser respeitado.

\section{g) O Brasil é um país dependente}

Além desses enunciados, há outros textos que colocam o Brasil em posição subalterna e dependente: é o caso, por exemplo, de uma matéria publicada, recentemente, em $O$ Estado de $S P(E S P)$, a respeito da ação contra o tráfico de drogas, por ocasião da visita do presidente da Colômbia. O jornalista transcreve a fala da embaixadora dos Estados Unidos no Brasil, apresentando as expectativas do governo americano com relação ao Brasil e, portanto, com relação aos brasileiros:

(S. 6) - Nós aplaudimos a disposição de participação que o presidente Lula da Silva tem demonstrado...."; [mais adiante:] "...queremos que ele e Uribe trabalhem juntos para desenvolver uma abordagem regional para o problema do narcotráfico, que afeta os dois países. (ESP, 7 de março de 2003)

Fica claro nessas falas - com verbos ativos na primeira pessoa do plural ("aplaudimos", "queremos") - o atravessamento do discurso do colonizador, que deve dizer ao outro (colonizado) o que deve fazer e avaliar o que é feito, ainda que saibamos que se trata de uma colonização econômica e política que coloca o outro (no caso, o Brasil) no lugar de devedor diante daquele (o americano) a quem, porque deve dinheiro, deve obediência. E o brasileiro se identifica com esse lugar de subserviência, como aponta também Backes (2000). 
h) O Brasil é campeão...

Trata-se, neste caso, do futebol e do "cibercrime", duas situações em que o Brasil consegue ser campeão. Com relação ao futebol voltaremos mais adiante. A respeito do cibercrime, referimo-nos especialmente a um texto escrito por um jornalista brasileiro que considera que "o cibercrime se origina do Brasil porque é um país industrializado. É uma espécie de crime do século 21". Fazendo menção ao Ato patriótico americano em vigor depois de 11 de setembro nos Estados Unidos, o jornalista, porta-voz do ponto de vista estrangeiro (ou melhor, americano), compara a ação dos hackers à dos terroristas, afirmando que o Brasil tornou-se uma "potência em hackers", porque é "o maior exportador de criminalidade via internet". Parece bastante providencial a seguinte fala do presidente do mi2g, D.K.Matai, transcrita nessa matéria:

(S. 7) - [Os brasileiros] não se importam muito com a qualidade de seus alvos. Estão mais interessados em quantidade. Querem ser conhecidos no mundo como aqueles que fazem o maior número de ataques. ( $F S P, 20 / 11 / 2002)$

O tom irônico do texto veiculado por termos como "campeão", "maior exportador", "potência", no exemplo acima referido, se completa quando se lê sobre qual produto ou atividade recaem: "cibercrime", "criminalidade via internet", "hackers", que transformam o Brasil e os brasileiros, tal como os que atingiram as Torres Gêmeas, em "terroristas", temíveis e perigosos, aos olhos dos americanos. Se a inteligência do brasileiro é reconhecida, ela está voltada para o mal e nem assim a sua ação recai sobre a qualidade: tal como no futebol, é a quantidade de ataques que interessa aos brasileiros. O caráter de consciência que o texto imprime a essas atitudes reforça ainda mais o sentimento de inferioridade do brasileiro frente ao americano que, afinal, parece ser campeão de tudo o que está voltado para a qualidade e para o bem...

Antes de passarmos ao item seguinte, convém assinalar que, se é verdade que subjaz aos textos jornalísticos analisados uma crítica feroz ao brasileiro - "espécie híbrida, meio malandra, meio diplomata" (FSP, 9/1/ 2000) -, é também verdade que, nos textos escritos pelos estrangeiros, aflora uma admiração que provém, muito provavelmente, de um desejo de ser o outro, diferente, exótico, com qualidades que desejam porque lhes faltam e que, ilusoriamente, os completariam. Se o sujeito deseja o gozo, que permanece como recalque no inconsciente, esse gozo é buscado e imaginado num lugar estranho, diferente, qual Pasárgada, onde não haveria lugar para interdições nem limites, onde supostamente tudo seria possível. E o Brasil é um desses lugares para muitos estrangeiros... 


\section{Representações do outro-estrangeiro}

Embora seja possível perceber, como já foi assinalado, a imagem que brasileiros fazem do outro (estrangeiro) e as representações que os estrangeiros fazem de si próprios e de sua cultura quando tratam do Brasil e dos brasileiros, foram analisados outras matérias jornalísticas em que tais representações se fazem mais explícitas. Procuramos, abaixo, sintetizálas, como na seção anterior, em alguns enunciados recorrentes.

\section{a) Os estrangeiros são superiores ao Brasil e aos brasileiros}

Este enunciado perpassa praticamente todos os demais. Ainda que se percebam - e se enunciem - falhas, defeitos nos povos admirados (europeus ou americanos), suas qualidades se sobressaem. É o que é possível perceber em textos que apontam para a posição de aparente igualdade que o Brasil assume com relação ao estrangeiro: numa matéria publicada em 1998, na Folha de São Paulo, por exemplo, fica claro que o Brasil assume uma posição de igualdade com os Estados Unidos quando se trata de futebol, o que faz pressupor que, nas demais situações, o Brasil não tem expressão alguma no contexto internacional - "não é idolatrado nem estimado como irmão", declara o texto escrito por um americano, e nós acrescentaríamos: a não ser nas situações em que ele causa prazer, como numa partida de futebol:

(S. 8) - O Brasil vira uma espécie de igual, as gritantes diferenças sociais e econômicas entre ele e os EUA parecem atingir aquele estranho patamar de idolatria e irmandade que os países do Primeiro Mundo têm entre si. Todos passam a gostar do Brasil /.../ Nesse momento, o Brasil tem uma cara jovem, simpática, uma cara talentosa, forte e virtuosa, que o americano adora. (FSP, 10/7/1998)

Observem-se as características de um país que agrada os americanos: cara jovem, simpática, talentosa, forte e virtuosa. As mesmas características, como sabemos, preponderam no imaginário do brasileiro não apenas com relação ao Brasil, mas também com relação ao indivíduo: ninguém ignora que muitas empresas escolhem seus funcionários pela faixa etária, mais do que pela competência profissional, afinal, num mundo de transformações aceleradas, só o jovem é capaz de se adequar e ter sucesso ou, o que parece mais verdadeiro, trabalhar para o sucesso da empresa -é ao menos o que faz crer a ideologia neoliberal que objetifica o ser humano, transformando em mercadoria ao lado de outras mercadorias (ROZITCHNER, 1989). 
É interessante observar que, no final desse texto, que parecia inicialmente querer mostrar a posição inferior que ocupa o Brasil nos EUA, emerge um surto de ufanismo:

(S. 9) - E quando Taffarel jogou a bola para o lado, todas as nossas almas de joelhos no chão de Manhattan sentiram um breve momento de identificação com aquilo que há de mais sublime, a honra de possuirmos uma identidade poderosa, jovem, inexperiente, imatura, cheia de erros, mas aberta e generosa. $(F S P, 10 / 07 / 1998)$

Nesse delírio de ufanismo, algumas características benquistas dos americanos permanecem ("identidade poderosa e jovem"), mas outras, negativas - (identidade) "inexperiente, imatura, cheia de erros" - emergem como consequiência da juventude do país, que nos distingue dos países do velho mundo, e, por isso mesmo, nos honra, como que para enaltecer duas outras qualidades, que, por oposição, não caracterizam as demais sociedades nem mesmo a americana: abertura e generosidade, qualidades que reforçam a identificação do brasileiro com o outro, estrangeiro, que tanto admira. Mais uma vez, é o futebol que realça as qualidades do povo brasileiro e o enche de orgulho. A imagem de campeão no futebol é parte pregnante da identidade do povo brasileiro, de tal modo que ele a assume sem questionamento, aceitando a sua posição de objeto de prazer para o outro.

\section{b) Os EUA e os americanos são bons e solidários}

Outro texto desta feita escrito por um jornalista brasileiro, intitulado "Brasileiro é falso bonzinho", segue o mesmo discurso de valorização do estrangeiro em detrimento da própria imagem: o Brasil é cruel, contrariamente aos EUA que oferecem tratamento gratuito a doentes de HIV, ainda que os beneficiados sejam "imigrantes ilegais, soropositivos e exilados sem direito a anistia". Observe-se um trecho extraído do mesmo texto:

(S.10) - O brasileiro gosta de se imaginar cordial, camarada, emotivo. Quando está no exterior, reclama da "frieza" do americano e do europeu. A verdade é que somos falsos bonzinhos: em meio à indiferença generalizada, direitos individuais são pisoteados todos os dias em grande escala. E tudo termina sempre em impunidade. ( $F S P, 3 / 3 / 1996)$

Observe-se a generalização que brota do substantivo precedido pelo artigo definido ("o brasileiro"), a quem se atribui uma certa dose de falsidade consciente, já que ele "gosta de se imaginar cordial, camarada, emotivo", por oposição ao europeu e ao americano que percebem "frios". 
Note-se que a matéria termina tentando amainar a crítica e mostrando que, apesar da indiferença que parece caracterizar o brasileiro, ainda há os que são generosos, pois participam de movimentos e se preocupam com os mais carentes (..), assim como se encontram brasileiros em Nova Iorque que ajudam outros a suportarem a AIDS. Mas quem é, de fato, digno de ser exaltado são os americanos e os EUA que possibilitam que tal aconteça, sem fazer discriminação. A idéia de falsidade, fingimento e, sobretudo pouca responsabilidade social que o articulista brasileiro atribui ao seu povo, embora não pareça a ele pertencer, vê-se ainda mais reforçada pela impunidade de "sempre". Observe-se o uso da terceira pessoa ("o brasileiro gosta, reclama"), seguido por um verbo na primeira pessoa do plural ("somos falsos bonzinhos"), cujo efeito de sentido se vê enfraquecido pela oração na voz passiva ("direitos individuais são pisoteados") que, mais uma vez, afasta o locutor, colocando-o fora do grupo responsável pelo desrespeito aos direitos do outro. Vale notar que o mesmo locutor, assumindo uma postura crítica, de alguém que observa, funciona no enunciado como autoridade que, por pertencer à sociedade brasileira, pode constatar e julgar com a suposta isenção necessária.

c) Os povos americano e europeu sabem se avaliar

Contrariamente ao brasileiro, os americanos e europeus são sensatos e, por isso mesmo, sabem se avaliar. Vejamos um excerto de um texto, escrito por um americano, que compara, de forma irônica, o brasileiro a outros povos:

(S.11) Ou seja, brasileiro é "avançado" sem saber, pelo menos de acordo com a pesquisa. Ele se acha ótimo, quase perfeito, mas, apesar disso, é incapaz de lidar com a modernidade. /.../ Não consigo imaginar um francês a dizer que os seus compatriotas são 100\%, mas inadaptados à modernidade, para dar um exemplo. Um americano, menos ainda. (ESP, 29/05/1999)

O tom irônico parece advir do uso das aspas no adjetivo "avançado", já que, de acordo com uma sondagem realizada em 1999, ele se acha "ótimo". O texto sugere que o brasileiro não é crítico a respeito de si, pois não é possível acreditar-se ótimo se "é incapaz de lidar com a modernidade". A comparação que o autor americano faz com outros povos (francês e americano) aponta para essa lacuna, imperdoável no mundo onde reina a técnica e a tecnologia, mas que, segundo o jornalista, parece irrelevante para os brasileiros. Portanto, os brasileiros ao mesmo tempo em que são pouco críticos (pois se acham ótimos) são pouco exigentes consigo mes- 
mos: não se preocupam em se sobressair no cenário mundial, globalizado. É evidente que esse discurso proferido por um estrangeiro silencia a verdadeira razão desse apagamento e dessa tendência ao acomodamento e à aceitação do lugar que lhe é imputado na esfera mundial, omitindo, dentre outros, o aspecto da exploração dos países menos desenvolvidos pelos países industrializados, que dominam a economia mundial. Não seria o julgamento exagerado sobre si mesmo, que o enunciador-jornalista imputa ao brasileiro - "ótimo, quase perfeito" -, uma forma de se valorizar, já que outros não o valorizam, de alimentar o narcisismo necessário à sobrevivência do sujeito?

\section{d) Tudo o que é estrangeiro (americano e europeu) é melhor}

Mais dois exemplos em que o caráter positivo do imaginário do brasileiro com relação ao estrangeiro salta aos olhos, ainda que opiniões negativas sejam explicitadas. Vejamos o primeiro:

(S.12) /.../ Quem vai ensinar à nova geração as "pommes soufflées" perfeitas, a omelete "baveuse", as massas folhadas, a técnica, a disciplina férrea e todo o resto?

Não sei as respostas, e cada um tem a sua. Minha esperança está na cara do francês que come, o seu prazer à mesa, o olhar entendido que lança para a outra. (Esta opinião vai contra outra, que acha a maioria do povo francês completamente ligado a tradições de uma época de escassez e incapaz de absorver novidades culinárias. Ver a quantidade de miúdos e o aproveitamento da comida em sopas e ensopados nos bistrôs simples e o menu repetido e sem inspiração). (FSP, 27/10/2000)

Exemplo interessante para perceber as identificações tanto positivas quanto negativas que despertam os franceses nos brasileiros. De um lado, o respeito à tradição, ao conhecimento secular da arte culinária que os torna entendidos e objeto de desejo (observem-se os adjetivos e sintagmas: "perfeitas", "disciplina férrea e todo o resto"), de outro, o mesmo respeito à tradição suscita críticas à sua incapacidade de absorver o novo, o que torna a cozinha francesa "repetida e sem inspiração". No primeiro caso, é preciso garantir a continuidade do que é bom, do que se tornou símbolo de um povo, pelo apagamento dos defeitos; no outro, ocorre o apagamento dessa simbolização, para enfatizar os defeitos; em ambos os casos, é o desejo do outro que permanece: outro que se gostaria de ser mas não se é, desejo que se concretiza na gratidão, manifestada pela simbolização, ou na inveja, manifestada pelo apagamento das qualidades...

Dito de outra maneira, tanto num como noutro caso, é a cultura brasileira que serve de parâmetro, ou seja, o que o brasileiro não é e gosta- 
ria de ser ou o que o brasileiro não é e diz não querer ser, talvez por seguir um modelo tipicamente americano que preconiza o "novo" em detrimento do velho, representado, no exemplo citado, pelo europeu (francês). Tratase aqui da famosa oposição entre velho e novo mundo, entre o passado e o futuro, entre a tradição e o progresso - dicotomias que aparentemente se excluem - mas que apontam para as identificações conflituosas que constituem a subjetividade.

\section{f) O brasileiro só tem a aprender com o estrangeiro (sobretudo com o} americano)

O texto denominado "Em Roma, como os romanos", de Otavio Frias Filho, que tece, na $F S P$, comentários interessantes a respeito dos estranhamentos dos americanos diante da cultura brasileira, termina com o seguinte parágrafo:

(S.13) - Se conseguirmos ser seletivos, temos muito a aprender com eles [os americanos]. Inclusive quanto às nossas próprias virtudes, que ressaltam por contraste à luz da devastação da subjetividade, da assustadora robotização de atitude e de mentalidade, que é o preço que eles pagaram para chegar ao sucesso material e ao topo do mundo.

Este recorte vem ao encontro da admiração do outro - "sucesso material"; "topo do mundo") -, que serve ou deveria servir sempre de parâmetro, inclusive para prevenir, com as consequiências de seus erros, comportamentos ou atitudes cujos efeitos poderiam ser desastrosos. Dirse-ia o conselho de alguém mais experiente que diz ao jovem para observar os pais e aprender com eles o que não devem fazer... esquecendo, é claro, que é preciso "matar o pai" (que simboliza a autoridade, a lei, as regras) para se singularizar.

\section{g) É bom ser brasileiro mas seria melhor ser estrangeiro}

Para terminar, embora muitos outros exemplos e até mesmo enunciados pudessem ser evocados, observe-se S.14, a respeito dos centros de Tradições Gaúchas, espalhados pelo país, que parece dar conta do desejo do outro expresso aqui por uma espécie de denegação:

(S.14) - É bom saber que os gaúchos podem mudar seu traje autêntico. É bom saber que eu posso ser gaúcho, se quiser. Pois eu não posso escolher ser sérvio. Nem posso escolher "pertencer" à etnia albanesa. Pena. (FSP, 20/6/1999)

A mobilidade dentro do país e a impossibilidade de mobilidade fora dele parece ser frustrante para o brasileiro, o que é sugerido pela exclamação "pena" e pela negação: "não posso escolher ser sérvio nem "per- 
tencer" à etnia albanesa". O uso das aspas aponta para o interdiscurso, mostrando a estranheza ou a impossibilidade de inserção numa etnia que nos escapa, mas que, justamente por isso, desejamos. Não estaria apontando esse enunciado para o desejo - cuja realização será sempre adiada - de um mundo homogêneo, completo, onde todos fossem iguais, cidadãos do mundo, sem limites nem fronteiras? E ao desejar esse impossível, não estaria, desejando o estabelecimento de uma língua franca, que possibilitasse a comunicação perfeita?

Entretanto, vale ressaltar que o texto faz referência à mobilidade dentro do país com relação aos trajes e danças populares, pois se sabe muito bem que a migração traz conseqüências de rejeição e discriminação e que o imaginário dos habitantes das diferentes regiões do país com relação às demais funciona de modo semelhante ao que caracteriza a relação entre os países dos Hemisférios Norte e Sul: o nordeste para o paulistano é o lugar do repouso, do sonho, da indolência, assim como o Brasil para os europeus; São Paulo para o nordestino é o lugar do trabalho, do futuro, da tecnologia, estereótipos que permanecem na memória discursiva e afloram nas atitudes ao dia a dia.

\section{h) Os franceses são antipáticos e arrogantes}

Convém observar que, quando se encontram referências a outros povos é para mostrar sua superioridade com relação aos brasileiros, e/ou criticar, reforçando estereótipos já existentes no imaginário do povo brasileiro ou construindo outros: por exemplo, "Mesmo que seja possível convencer os franceses a estudar línguas estrangeiras" - o que pressupõe que os franceses não conseguem aprender uma língua estrangeira -, "esperamos torná-los mais amáveis e respeitosos em relação à cultura dos visitantes estrangeiros", o que retoma a intolerância dos franceses para com os estrangeiros. Esse enunciado se repete na chamada que sintetiza o texto:

\section{(S.15) - Combate à cara feia}

Uma campanha tenta convencer os franceses a ser menos arrogantes e a tratar melhor os turistas. (Veja, 30/8/1995)

Essas características - arrogância e falta de amabilidade e respeito para com os turistas - reaparecem nas respostas a questionários submetidos a professores e alunos, embora o caráter positivo e elogiável do povo francês encontre maior espaço no imaginário de alunos e professores de francês (CORACINI, 2003), o que talvez se deva à identificação do professor com a língua francesa, ao caráter exaltador dos livros didáticos com relação aos falantes nativos da língua em questão, trazendo apenas características positivas e coerentes do país e do povo, cujo efeito é, sem a 
menor dúvida, simplificador. Rufino (2002) faz um estudo semelhante com relação ao livro didático de língua inglesa, mostrando o fetiche que a envolve com consequiências importantes na constituição do imaginário de quem estuda ou estudou a língua.

\section{CONCLUSÃO}

Procuramos mostrar que, nos registros analisados, os estrangeiros colocam o Brasil e os brasileiros em posições subalternas: apenas em situações onde o lúdico é que está em jogo, é que o Brasil, fetichizado, se destaca e, ainda assim, para "servir" aos outros. É um pouco como na relação do senhor e dos servos: estes são valorizados na medida em que servem ao senhor. Aliás, é possível afirmar que, quando há referências, na mídia impressa, a aspectos interessantes do Brasil e do povo brasileiro, elas têm um caráter de incentivo ao turismo: visão idílica que silencia os conflitos, os problemas. No mais, a crítica é ferrenha e o parâmetro é sempre a própria cultura, a cultura "superior" do estrangeiro que escreve. Quando se abordam a miséria, os problemas sociais, silenciam-se as causas e joga-se sempre a culpa no outro, isto é, no brasileiro, na cultura brasileira que é acusada de ser indolente e corrupta, evitando, a todo custo, analisar as verdadeiras causas.

Entretanto, o desejo do outro é perceptível tanto no estrangeiro com relação ao Brasil quanto do brasileiro com relação ao estrangeiro: a ânsia de preenchimento da falta que constitui uns e outros move os sujeitos em direção ao outro que já constitui o seu inconsciente. Para o estrangeiro, o Brasil é o lugar do exótico, da permissividade, da ausência de lei e, portanto, é o lugar onde podem fazer o que lhes é interditado no país de origem: lugar de passagem e de gozo, de exploração e de proveito.

Para o brasileiro, o estrangeiro constitui o paraíso perdido, voz (discurso) do colonizador que, um dia, partiu de seu país de origem em busca do gozo, da permissividade, da impunição, enfim, da mãe, ou de um nome, de terras de que pudesse ser proprietário, em busca do pai que não conseguiu encontrar (CALLIGARIS, 1996), vozes que permanecem vivas no inconsciente, como modelo de virtudes que desejaria imitar, mas que permanece recalcado como o inatingível que abandonou, muitas vezes contra a vontade. A primeira voz explicaria, segundo Calligaris (op. cit.), o jeitinho brasileiro, o caráter malandro, que burla a lei e tira proveito de tudo; a segunda, explicaria a tendência, contraditória, a defender a força, a lei, a ordem, ainda que à custa de um governo ditador. Mas, é preciso considerar nosso desejo não está apenas no estrangeiro (europeu) de cujos anseios e representações se originou o povo brasileiro, mas também no 
americano, que nos constitui por sua superioridade econômica, espírito prático, ligado à globalização e ao sucesso tecnológico, marca registrada da modernidade. Imbricada nessas vozes, não se pode deixar de ouvir a voz do colonizado, daquele que, para sobreviver, precisa aceitar o lugar que the é concedido, ainda que esse lugar o transforme em objeto de prazer para o outro: afinal, esse também é um modo de garantir sua existência.

Ou então, como foi possível constatar, o estrangeiro permanece no imaginário do brasileiro, como o explorador, o indesejável, aquele que se gostaria de esquecer, de banir, porque perturba, exibe a própria fragilidade indesejada, mas que está aí, no inconsciente, na memória, reminiscências de um passado esquecido, mas que se faz presente o tempo todo no inconsciente, que pode se manifestar em "ressentimento" ou numa certa implicância que o leva a ressaltar os defeitos do outro, suas falhas e sofrimentos, na busca de um consolo para o seu próprio sentimento de inferioridade; e esse ressentimento ou essa implicância o faz viver, dá sentido à sua existência e lhe imprime um sentimento de identidade.

A partir dos resultados aqui comentados, é possível reconhecer, então, pontos de identificação de uns e de outros que nos permitem afirmar algo sobre a "identidade" do brasileiro: constituídos pela imbricação de discursos outros (região do interdiscurso) - dentre os quais o discurso do estrangeiro -, os sujeitos brasileiros são atravessados, por um lado, pelo mito do falante nativo e do estrangeiro (o que vem de fora é sempre melhor) e, de outro, por um nacionalismo exacerbado que se traduz por elogios e qualidades atribuídas a todo produto nacional e, portanto, à língua oficial do país de origem, o que também aponta para a falta constitutiva e para auto-representações "negativas" que se desejaria apagar a todo custo, mas que ali permanecem mutilando e perturbando a auto-imagem. E tudo isso é o brasileiro: aproveitador, gozador e, ao mesmo tempo, rigoroso; presunçoso e rebelde, mas submisso, entregue a um imaginário que engrandece o outro deixando marcas de seus recalques e frustrações; solidário e, ao mesmo tempo, fingido, falso; caloroso, indiferente à miséria que o cerca; contraditório, mas coerente com a constituição conflituosa do sujeito.

É nessa região de conflitos e tensões - entre a extrema valorização do outro, da cultura e da língua do outro e a extrema valorização da própria cultura e, conseqüentemente, entre a desvalorização da própria cultura e a desvalorização do outro -, onde se dá o deslizamento de sentidos, que se configura a subjetividade e a identidade do sujeito e da nação e, portanto, do brasileiro e do Brasil. Por tudo isso, acreditamos ser possível afirmar com Backes (2000, p.156) que "ser brasileiro é obra do desconhecido, negado, recalcado, esquecido... como, aliás, tudo aquilo que escapa à soberania do sujeito consciente e só se revelará involuntariamente". 
Em suma, chama a atenção o fato de existirem poucos textos, escritos por brasileiros, que reagem ao discurso do colonizador, que os relega a uma posição subalterna; ao contrário, a maioria deles dá mostras da internalização desse discurso que já se fez corpo: o brasileiro, em geral, e cada um em particular se sente (consciente ou inconscientemente inferior diante do estrangeiro europeu e americano que admira e anseia como o paraíso perdido da totalidade impossível, do seio materno do conforto e do repouso. Em lugar desse conforto, reata o recalque e o sentimento da falta que impede que se valorize a própria cultura, se reaja e se encontrem soluções, ainda que provisórias, para os problemas - sociais, políticos, econômicos e educacionais - que mutilam e imobilizam o povo brasileiro diante do outro, sem se dar conta de que é preciso "matar o pai" para que ele possa assumir sua própria existência, embora esse "pai” permaneça transformado - na constituição de sua subjetividade.

\section{BIBLIOGRAFIA}

BACKES, Carmen. O que é ser brasileiro? São Paulo, Escuta, 2000.

BHABHA, H. Locais da Cultura. Traduzido por Myriam Ávila e outros. Belo Horizonte, Ed. da UFMG, 1998.

CALLIGARIS, Contardo. Hello Brasil! São Paulo, Escuta, 1996.

CORACINI, Maria José R. F. (org.) Discurso e Identidade: (des)construindo subjetividades. Campinas, Chapecó, Ed.da Unicamp e Argos, 2003.

DERRIDA, Jacques. Le monolinguisme de l'autre. Paris, Galilée, 1997.

FOUCAULT, Michel. Microfísica do Poder. Rio de Janeiro, Graal, 1979.

FREUD, S. O mal-estar na civilização. Trad. de José Octavio de Aguiar Abreu. Rio de Janeiro, Imago, 1997.

HALL, Stuart. Identidades culturais na pós-modernidade. Trad. de Tomaz Tadeu da Silva \& Guacira L. Louro. Rio de Janeiro, DP\& A Editora, 1997.

LACAN, Jacques. O estádio do espelho como formador da função do eu. In: Lacan, J. Escritos. Trad. por Vera Ribeiro. Rio de Janeiro, Jorge Zahar, 1998.

MARIANI, Betânia. O PCB e a Imprensa. Rio de Janeiro, Revan; Campinas, Editora da Unicamp, 1999.

MELMAN, Charles. Imigrantes: incidências subjetivas das mudanças de língua e país. São Paulo, Escuta, 1992. 
NASIO, Juan David. Lições sobre os 7 conceitos cruciais da psicanálise. Trad. por Vera Ribeiro. Rio de Janeiro, Jorge Zahar, 1995.

REVUZ, C. A Língua estrangeira: entre o desejo de um outro lugar e o risco de exílio. In: Signorini, I. (org.) Lingua (gem) e Identidade. Campinas, Mercado das Letras, 1998. p. 213-230

ROZITCHNER, León. Freud e o problema do poder. Trad. por Marta Maria Okamoto e Luiz Gonzaga Braga. São Paulo, Escuta, 1989.

RUFINO, Karim B. P. L. Livros didáticos de língua inglesa: uma análise discursiva das representações da diversidade cultural. Dissertação de Mestrado. FFLCH - USP, 2002.

SILVA, Tomaz Tadeu da (org.). Identidade e Diferença. Petrópolis, Vozes, 2000.

SOUZA, O. Fantasias de Brasil. São Paulo, Escuta, 1994. 